\title{
ANTECEDENTS OF CONSUMER TRUST IN MOBILE PAYMENT ADOPTION
}

\begin{abstract}
This study empirically examines the role of consumer trust and its antecedents in determining consumers' intention to adopt mobile payment. This research proposes that consumers' willingness to adopt mobile payment depends on their assessment of the trustworthiness of mobile service provider and vendor, their assessment of the functional reliability of mobile payment systems as well as their general disposition to trust and their cultural background, in particular, uncertainty avoidance. Data were gathered from 302 participants in Auckland, New Zealand. Results show that all five sets of trust antecedents influence the development of trust and trust is an important predictor of intention to adopt mobile payment. Both theoretical and practical implications are discussed.
\end{abstract}

Keywords: Adoption; Culture - uncertainty avoidance; Mobile payment; Trust

\section{INTRODUCTION}

Mobile payment is defined as a type of payment method for which payment data and instructions are conducted through mobile devices [46]. It can be broadly classified into two categories: point of sale (POS) contactless payments and mobile remote payments [46]. The POS contactless payment service requires both buyer and seller's presence to complete transactions. The technology applied here is contactless radio technologies including near field communication (NFC), Bluetooth or infrared technology for data transfer. Examples of this payment method include paying for groceries at supermarkets or making purchases at retail stores. The mobile remote payment service represents payment that is made through either SMS (e.g., paying for car parks or at petrol stations) or wireless application protocols (WAP) (e.g., using mobile Internet to make purchases).

Prior literature suggests that lack of trust is one of the most frequently cited reasons for consumers' decisions not to purchase products from e-commerce sites [21, 34]. Trust can serve as an informal control mechanism to reduce friction, limit opportunistic behaviours, encourage future transactions and help build long-term relationship [21]. Therefore, to successfully diffuse mobile payment services, it is crucial to investigate how consumer develops mobile payment trust. Previous studies show trust is an important predictor of mobile payment adoption intention [1, 7, 29, 38, 59, 62]. However, few studies explore trust antecedents in the mobile payment context. To address this gap, the objective of this research is to explore the antecedents of trust and its influence on mobile payment adoption. 
Trust is context specific and a multi-dimensional construct [21]. To fully understand the formation of consumer trust, it should be examined with multiple perspectives. Chandra et al. [7] examine two broad dimensions of trust antecedents in the mobile payment context, which are the characteristics of mobile service provider and the characteristics of mobile technology. They find that those two dimensions of trust antecedents have significant influence on formation of consumer trust. In their study, they suggest that future studies should include mobile payment vendors whom the purchases are made from as another component of trust antecedents. As a response to their call, this research extends the work of Chandra et al. [7] by incorporating the characteristics of mobile payment vendor. As mentioned earlier, trust is a multi-dimensional construct. Disposition to trust has been shown to influence trust in IS studies $[16,32,43]$. However, to the best knowledge of the authors, it has not been examined in the mobile payment context. In addition, GrabnerKräuter and Kaluscha [21] find that trust studies in IS do not pay much attention to the influence of culture on trust. Dahlberg et al. [12] also suggest future studies should investigate how culture influences mobile payment adoption. Therefore, this research examines five dimensions of trust antecedents which are the characteristics of mobile service provider, mobile payment vendor and mobile technology, disposition to trust and culture. The research questions are:

1. What constitute mobile payment trust?

2. What is the influence of trust on mobile payment adoption intention?

The remainder of this paper is organised as follows. The next section presents the theoretical development of this study, followed by the research model and the hypotheses. Next, the research methodology and the results are presented. The paper concludes by offering theoretical and managerial implications of this study.

\section{THEORETICAL DEVELOPMENT}

Trust means secure willingness to depend on a trustee because of that trustee's perceived characteristics [53]. In the IS literature, McKnight et al. [40, 42, 43] develop a trust typology and conceptualise trust as trusting beliefs, trusting intentions, and trusting behaviours. They posit that these three concepts are interrelated. The trusting beliefs affect trusting intentions and trusting intentions lead to trusting behaviours. Trust is not a static but a dynamic phenomenon and, as such, different phases of trust should be distinguished and specified [21]. Given that this study focuses on pre-adoption of mobile payment, this research will focus on initial trust formation.

Mcknight et al. [43] postulate that initial trust primarily involves trusting beliefs and trusting intentions. They argue that trusting beliefs are a strong determinant of trusting intentions. In context of this study, trusting beliefs refer to the benevolence, competence and honesty of mobile service provider and vendor perceived by consumers. Trusting intentions refer to consumer's willingness to depend on mobile service provider or vendor in a given situation. In a mobile payment eco-system, consumers can be put in a vulnerable position because they do not have much control over transactions. Successful completions of mobile payment transactions depend on faithful and ethical conducts of mobile service providers and vendors as well as reliable mobile technology. However, there are no guarantees that mobile service providers and vendors will live up to consumers' expectations. Consumers may have concerns on possible opportunistic behaviours of mobile 
service providers and vendors. They may have concerns on privacy issues such as their purchases might be tracked by service providers and then they would begin to receive advertisements [11]. Dahlberg et al. [11] find that consumers are willing to conduct mobile payment transactions with vendors who are well-known and established companies. Therefore, with those vendors which consumers are not familiar with, consumers may have doubts on how they implement mobile payment technology. Therefore, if consumers perceive that a mobile service provider or vendor is not trustworthy, they will have doubts in using mobile payment as a means to conduct financial transactions. Hence, when consumers decide to place trust in mobile payment system, they develop trust through evaluating the trustworthiness of mobile service providers and mobile payment venders.

The underlying mobile technology in the mobile payment system is the mobile Internet (e.g., 3G networks). Successful completion of mobile payment transactions depend on the reliable and stable functioning of mobile technology. Consumers may have doubts on stability of mobile technology functioning. They may imagine that there may a failure of mobile network connection in the middle of a transaction or transaction errors (e.g., delays in the system) which may cause repeated purchases and duplicate charges [11]. These doubts may mean that consumers are unlikely to consider mobile technology as a secure means to conduct financial transactions. Consequently, they will not trust a mobile payment system.

Structural assurance, as a type of institution-based trust, refers to safeguards such as regulations, laws, and guarantees that make the trustors feel safe to do transactions with trustees [43]. It helps to reduce uncertainties associated with technology disruption during transaction process. At the early stage of mobile payment adoption, consumer trust may rely on the reliability and stability of mobile technology. Therefore, the safeguards of the technology or the regulations of the business environment may help consumers engender trust and reduce their uncertainties. Hence, the assessment of mobile technology is another important evaluation when consumers to decide to place trust in a mobile payment system.

McKnight et al. [41, 43] note that disposition to trust is important in the initial trust formation. It is a type of personality-based trust and it is rooted in the trustors themselves (i.e., background, culture). When one party (i.e. consumers) does not have direct experience with or first-hand knowledge of the other party (i.e., mobile payment system), trust is mostly developed through one's disposition to trust that enables one to trust the other party. For those consumers who have a higher degree of disposition to trust, they tend to easily trust others in their daily life and may place a higher level of trust in mobile payment system. On the other hand, consumers who have a lower degree of disposition to trust tend to resist trusting others in their daily life. As a result, it is likely that they will place a lower level of trust in mobile payment system.

Doney et al. [14] posit that culture and trust are closely related. Previous e-commerce studies find that culture plays an important role in the formation of trust $[9,30,60]$. Among Hofstede's [26] cultural dimensions, uncertainty avoidance has been found to have the most significant influence on trust [5]. Uncertainty avoidance is related to the concept of risk, particularly risk preference and risk-reducing strategies [14]. Srite and Karahanna [58] refer to uncertainty avoidance as the level of risk accepted by individuals when they are in uncertain situations. At the early stage of mobile payment adoption, consumers may have uncertainties regarding the stable functioning of mobile technology or uncertainties around faithful conducts of mobile service provider and vendor. As a result, they may perceive a 
mobile payment system as risky to conduct any transactions. The degree of uncertainty avoidance reflects the extent that an individual is willing to tolerate risks under such uncertain situations. Consumers from high uncertainty avoidance culture tend to avoid risks and, in contrast, consumers from low uncertainty avoidance culture are likely to take more risks. In other words, consumers from high uncertainty avoidance culture may have a lower level of trust and consumers from low uncertainty avoidance culture may have a higher level of trust.

To conclude, to provide a more comprehensive understanding of how trust is formed at an early stage of mobile payment adoption, this research proposes a model to examine the influence of consumers' trusting beliefs of the characteristics of mobile service provider, mobile payment vendor and mobile payment technology on the development of mobile payment trust. In addition, this study also investigates how an individual's disposition to trust and the degree of uncertainty avoidance affects trust formation.

\section{RESEARCH MODEL AND HYPOTHESES}

\section{Research Model}

This research proposes that trust is a key facilitator of mobile payment adoption and the initial trust of mobile payment is developed through consumer's trust perceptions of mobile service provider, mobile payment vendor, and mobile technology. In addition, initial mobile payment trust depends on consumers' cultural background and their disposition to trust. Figure 1 presents the research model. Table 1 lists the definitions of key constructs in the model.

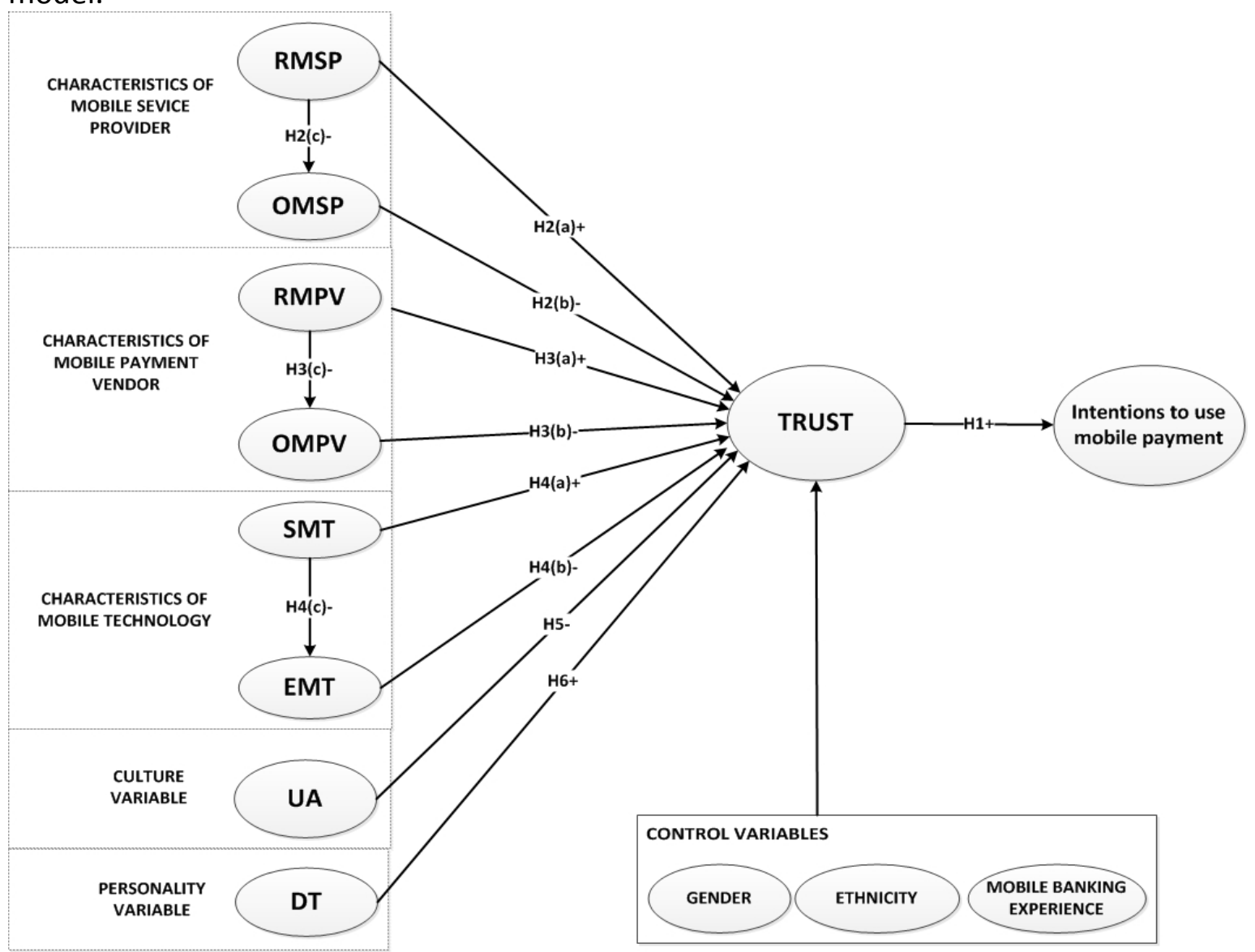

FIGURE 1: Research Model of Mobile Payment Adoption 
TABLE 1: Definitions of Key Constructs

\section{Construct}

Perceived

Reputation of

Mobile Service

Provider (RMSP)

Perceived

Opportunism of

Mobile Service

Provider (OMSP)

Perceived

Reputation of

Mobile Payment

Vendor (RMPV)

Perceived

Opportunism of

Mobile Payment

Vendor (OMPV)

Perceived Structural

Assurance (SMT)

Perceived

Environmental Risk

(EMT)
Definition

Reference

The extent to which consumers believe in the

mobile service provider's competency, honesty,

and benevolence.

Possible opportunistic behaviour of the mobile

service provider in relation to the consumer. It

refers to the consumer's risk in transacting with a

mobile service provider who might inappropriately

exploit the consumer's vulnerabilities.

The extent to which consumers believe in the

mobile payment vendor's competency, honesty,

and benevolence.

New construct, adapted from

[7]

Possible opportunistic behaviour of the mobile

payment vendor in relation to the consumer. It

refers to the consumer's risk in transacting with a

New construct, adapted from

[7]

mobile payment vendor who might inappropriately exploit the consumer's vulnerabilities.

The consumer's perception about the institutional

$[7,42]$

environment that all structures such as

guarantees, regulations, and promises are

operational for safe, secure and reliable transactions.

Risk associated with the underlying mobile

Internet technological infrastructure.

Environmental risks refer to the transaction

security related risks faced by consumers while

using a mobile payment service through a wireless

network.

Consumer Trust in

Mobile Payment

(TRUST)

Espoused

Uncertainty

Avoidance (UA)

The belief that mobile payment transactions will

be accomplished reliably.

This dimension examines the extent to which one

[58]

feels threatened by ambiguous situations. The

level of risk accepted by an individual can be

gleaned by one's emphasis on rule obedience,

ritual behaviour, and labour mobility.

An individual's ability and willingness to form trust

in general. This ability is a personality trait formed

through an individual's lifetime.

\section{Hypotheses Development}

Lack of trust is considered to be an obstacle to consumer's technology adoption. A number of IS studies demonstrate that trust has a positive relationship with the intention to 
adopt technology $[5,20,27,30,34,43]$. Studies in the mobile payment context also show that trust is a key predictor of mobile payment adoption $[7,56,62]$. Thus,

H1: Consumer trust is positively associated with the intention to adopt mobile payment.

The perceived reputation of mobile service provider (RMSP) is defined as "the extent to which consumers believe in the mobile service provider's competency, honesty, and benevolence" [7: p. 565]. When consumers do not have previous experience with a firm, they rely on its reputation to evaluate its trustworthiness [43]. Previous studies in ecommerce have shown that reputation of a firm positively associates with consumer online trust [3, 33]. Ba [3] states that if consumers perceive a bad reputation of an online bank, they will be discouraged from conducting online transactions. In a mobile banking study, Liu et al. [35] find a positive relationship between the reputation of a mobile banking service provider and consumer trust. Based on these empirical findings, we believe that if consumers perceive that a mobile service provider has good reputation, they are likely to trust the mobile payment service it provided and, by extension, the mobile payment system. Therefore, we posit that the reputation of a mobile service provider has direct positive influence on consumer's trust in mobile payment. Thus,

H2a: $\quad$ Perceived reputation of the mobile service provider is positively associated with the level of consumer trust in mobile payment.

The perceived opportunism of mobile service provider (OMSP) is defined as "possible opportunistic behaviour of the mobile service provider in relation to the consumer" [7: $p$. 565]. Pavlou et al. [48] report a negative relationship between a web vendor's opportunism and consumer trust in online shopping. Mukherjee and Nath [45] find that if consumers believe a bank is engaging or may engage in opportunistic behaviour, they are likely to lower their trust in online banking. Similarly, Chandra et al. [7] find a negative relationship between mobile payment trust and perceived opportunism of mobile service provider in Singapore. If consumers suspect that there might be opportunistic behaviour conducted by service providers, they may perceive a mobile payment system as too risky to conduct any transactions with and consequently they are more likely not to trust mobile payment. Therefore,

$\mathrm{H} 2 \mathrm{~b}$ : $\quad$ Perceived opportunism of the mobile service provider is negatively associated with the level of consumer trust in mobile payment.

A good reputation of a firm is viewed as an asset to that firm. Siau and Shen [57] claim that a good reputation of a firm implies the integrity of that business that help foster consumer trust in mobile commerce. Ba and Pavlou [4] suggest that a trustor who believes that a trustee with a good reputation is less likely to engage in dishonest or opportunistic behaviour in online transactions. Jarvenpaa et al. [27] find a negative relationship between the reputation and the opportunism of a web vendor in online shopping. Chandra et al. [7] also report similar findings in the mobile payment context. Therefore,

$\mathrm{H} 2 \mathrm{c}$ : $\quad$ Perceived reputation of the mobile service provider is negatively associated with the level of its perceived opportunism.

Gefen [17] suggests that vendor trust in e-commerce consists of competence, integrity and benevolence. Applying this conceptualisation in mobile commerce, we define the reputation of mobile payment vendor (RMPV) as the extent to which consumers believe in 
the mobile payment vendor's competency, honesty and benevolence [7, 17]. Doney and Cannon [14] note that the seller's reputation is an antecedent of trust in a traditional buyerseller relationship. Previous IS research also confirms a positive association between a seller's reputation and buyer's trust in e-commerce [19, 27, 47]. In the context of mobile commerce, vendor trust has found to be an important antecedent of trust in mobile banking [35] and mobile payment [1]. Therefore,

H3a: Perceived reputation of the mobile payment vendor is positively associated with the level of consumer trust in mobile payment.

The perceived opportunism of mobile payment vendor (OMPV) refers to possible opportunistic behaviour made by a mobile payment vendor. As discussed earlier, opportunistic behaviours include the trustee's distortion of information and failing to fulfil promises and obligations made to the trustor [28]. Grazioli and Jarvenpaa [22] find that perceived opportunistic behaviours made by Internet vendors weaken the relationship between trust in Internet vendors and trust in Internet shopping. Other studies also find a direct relationship between opportunism behaviours and trust in online shopping [48] and online banking [45]. If consumers perceive any opportunistic behaviour conducted by mobile payment vendors, they are likely to place lower trust in mobile payment. Therefore,

$\mathrm{H} 3 \mathrm{~b}$ : Perceived opportunism of the mobile payment vendor is negatively associated with the level of consumer trust in mobile payment.

Jarvenpaa et al. [27] demonstrate that the perceived reputation of Internet vendors is negatively correlated with their opportunistic behaviours. They argue that Internet vendors with good reputation are perceived to be reluctant to put their reputation at risk by engaging in opportunistic behaviours. Similar findings are also reported in e-commerce [4] and mobile commerce studies [7, 57]. By applying this logic to the mobile payment context, we believe mobile payment vendors with good reputation will be less likely to conduct opportunistic behaviours and jeopardise their reputation. We believe that if consumers perceive a higher reputation of a mobile payment vendor, they will perceive lower opportunistic behaviours of that vendor. Therefore,

H3c: Perceived reputation of the mobile payment vendor is negatively associated with the level of its perceived opportunism.

The perceived structural assurance (SMT) is defined as "consumers' perception about the institutional environment that all structures like guarantees, regulations, and promises are operational for safe, secure and reliable transactions" [7: p. 565]. Structural assurance can discourage possible opportunistic behaviour of the trustee parties [31]. Structural assurance is critical in shaping initial trust in technology and protecting consumers from systemspecific uncertainties and risks [42]. Previous IS research shows that structural assurance is an important antecedent of trust [7, 34, 42, 32, 31, 35, 49, 61]. Following this line of argument, we believe that consumers will have a higher level of trust in a mobile payment system if they believe that the structural assurance of mobile payment technology will provide them with safe, secure and reliable transactions. Therefore,

H4a: Perceived structural assurance is positively associated with the level of consumer trust in mobile payment.

The perceived environmental risk (EMT) is defined as risk associated with the underlying technological infrastructure including "the transaction security related risks faced by 
consumers while using mobile payment services through a wireless network" [7: p. 565]. Siau and Shen [57] argue that mobile technology related risks such as service breakdown of the wireless communication network and loss of transactions may lead consumers to have doubt in mobile technology and its ability to deliver services. As a result, consumer trust will likely be reduced. Chandra et al. [7] find a negative relationship between environmental risk and trust. In this study, we believe that consumers will have lower trust confidence in conducting transactions using mobile payment if they perceive high risks associated with the general environment of a mobile payment system. Therefore,

H4b: Perceived environmental risk is negatively associated with the level of consumer trust in mobile payment.

Structural assurance in the form of third-party guarantees mitigates technological risks. Luo et al. [36] find that consumers who have strong trust in structural assurance (i.e., legal and technology structures of mobile Internet) believe that their financial and personal data will be protected against transaction loss. In particular, their study shows that structural assurance of mobile wireless Internet lowers the level of perceived risks in mobile banking. Kim et al. [31] find that the presence of third-party guarantees lowers perceived risks in an online shopping environment. Similarly, Chandra et al. [7] report a negative relationship between perceived structural assurance and perceived environmental risk in the mobile payment context. Therefore,

H4c: Perceived structural assurance is negatively associated with perceived environmental risk in mobile technology.

Hofstede [26] argue that people from high uncertainty avoidance culture have lower uncertainty tolerance, higher structural needs (i.e., rules and regulations), and stronger faith in institutions than people from low uncertainty avoidance culture. This may suggest that, in new technology adoption, consumers from high uncertainty avoidance culture may need various means of assurance to trust new technology than consumers from low uncertainty avoidance culture. Vance et al. [60] find a direct relationship between uncertainty avoidance and trust in the mobile commerce context. We believe that consumers from high uncertainty avoidance culture may have lower mobile payment trust compared with consumers form low uncertainty avoidance culture. Therefore,

H5: Espoused uncertainty avoidance is negatively associated with the level of consumer trust in mobile payment.

As part of personality trait, disposition to trust is described by McKnight et al. $[42,43]$ as one's preference to show faith in humanity and to espouse a trusting stance toward others. They postulate a positive relationship between disposition to trust and trust in online shopping websites. Several IS studies have confirmed this relationship in e-commerce contexts $[16,19,32]$ and in mobile banking [61]. Extending this logic to the mobile payment context, we believe consumers with higher disposition to trust are more likely to trust mobile payment than those with lower disposition to trust. Therefore,

H6: The disposition to trust is positively associated with the level of consumer trust in mobile payment.

In addition to the previously discussed antecedents, two demographic variables and one experiential variable are included as control variables on consumer trust in mobile payment. These variables are gender and ethnicity as well as consumers' experience with mobile 
banking. The inclusion of these variables is supported by previous IS adoption studies in the literature. Salo and Karjaluoto [54] suggest that individual demographics have strong influence on the development of trusting belief. Gender has shown to have an impact on trust in IT adoption studies $[2,18]$. Dabholkar [10] suggests that consumers' experience with a similar technology is one of the factors influencing their trust in a new technology. Chandra et al. [7] show that consumers who have experiences with mobile Internet have higher trust in mobile payment systems compared to inexperienced consumers.

\section{RESEARCH DESIGN}

Survey was applied to empirically test the research hypotheses. Existing survey scales from extant literature were adapted for this study, whenever possible. Measures of characteristics of the mobile service provider (RMSP and OMSP) and characteristics of mobile technology (SMT and EMT) were modified from Chandra et al. [7]. Measures for characteristics of the mobile payment vendor were adapted from Chandra et al.'s [7] study to reflect the context of our study. Measures for uncertainty avoidance (UA) and disposition to trust (DT) were adapted from validated measures from Srite and Karahanna [58] and McKnight et al. [42] respectively. A pilot study was conducted to pre-test the instrument. 15 undergraduate students who are part of the target age groups participated in the pilot study. The feedback from the pre-test was used to change the layout of the questionnaire to improve readability and clarity.

\section{Data collection and analysis}

A sample of undergraduate students from two major universities in Auckland, New Zealand was chosen for the survey. Young adults were chose as the sample because they are among potential adopters of mobile payment and are more interested to adopt mobile payment than other age groups $[44,55]$. In particular, young adults believe that mobile commerce is much more convenient than traditional forms of commerce and they enjoy using mobile devices to do online shopping [44]. Paper questionnaires were distributed to students on campuses. Overall, 302 completed questionnaires were obtained and used in data analysis.

Partial least square structural equation modelling (PLS-SEM) were employed to test the hypotheses. With respect to covariance-based SEM (CB-SEM), PLS-SEM is more robust and can accommodate certain data characteristics, such as non-normally distributed data [23]. PLS-SEM supports structural models that have both formative and reflective constructs [23]. Disposition to trust is a formative construct in our study. Therefore, we believe that PLSSEM is an appropriate method for this study.

SmartPLS $2.0 \mathrm{M} 3$ [52] was used to perform data analysis. We used the bootstrapping technique with 5,000 resamples to determine the significance levels for loadings, weights and path coefficients [24].

\section{RESULTS}

\section{Demographics}

The sample from 302 respondents has a relatively equal split between male (50.3\%) and female (49.7\%). The three main ethnic groups in the sample are Asian (41.4\%), European 
(29.8\%) and Maori/Pacifica (17.6\%). Overall, $62.1 \%$ of participants have experience with mobile banking.

\section{Measurement Model}

The theoretical model includes nine reflective constructs and one formative construct (Disposition to trust) (see Table 2). Henseler et al. [25] suggest that a reflective and formative measurement model should be evaluated differently. Follow the procedures outlined by Hair et al. [24] for evaluating PLS-SEM models, four types of validity tests were carried out to validate reflective constructs: indicator reliability, internal consistency reliability, convergent validity and discriminant validity. For the formative construct, indicators' weights, loadings and their significance were examined and multicollinearity was tested.

For reflective constructs, the loadings of the measurement items on their latent constructs and their composite reliability are reported in Table 2 . The values of the loadings range from 0.72 to 0.97 , which are above the recommended threshold of 0.70 , indicating that validity and reliability are confirmed. The values of the composite reliability (CR) range from 0.81 to 0.96 , which are above the acceptable value of 0.70 , indicating that internal consistency is confirmed. The convergent reliability is tested by the average variance extracted (AVE) using the recommended threshold of 0.50. The values of AVE range from 0.70 to 0.91 , suggesting that convergent reliability is acceptable. To evaluate discriminant validity, we check whether the square root of AVE of each construct is larger than the correlation of the construct with other constructs. The bolded figures along the diagonal in Table 3 indicate that the square root of AVEs exceed the off-diagonal correlations between the constructs. Hence, the discriminant validity is confirmed. 
TABLE 2: Item Loadings, AVE and Composite Reliability (CR)

\begin{tabular}{|c|c|c|c|c|}
\hline CONSTRUCTS & INDICATORS & LOADINGS & AVE & CR \\
\hline \multirow{4}{*}{ EMT* } & EMT2 & 0.72 & \multirow{4}{*}{0.72} & \multirow{4}{*}{0.91} \\
\hline & EMT3 & 0.89 & & \\
\hline & EMT4 & 0.86 & & \\
\hline & EMT5 & 0.91 & & \\
\hline \multirow{3}{*}{ INTENTION } & INT1 & 0.95 & \multirow{3}{*}{0.88} & \multirow{3}{*}{0.95} \\
\hline & INT2 & 0.95 & & \\
\hline & INT3 & 0.92 & & \\
\hline \multirow{3}{*}{ OMPV } & OMPV1 & 0.90 & \multirow{3}{*}{0.80} & \multirow{3}{*}{0.92} \\
\hline & OMPV2 & 0.90 & & \\
\hline & OMPV3 & 0.88 & & \\
\hline \multirow{3}{*}{ OMSP } & OMSP1 & 0.83 & \multirow{3}{*}{0.70} & \multirow{3}{*}{0.87} \\
\hline & OMSP2 & 0.84 & & \\
\hline & OMSP3 & 0.85 & & \\
\hline \multirow{3}{*}{ RMPV } & RMPV1 & 0.94 & \multirow{3}{*}{0.91} & \multirow{3}{*}{0.96} \\
\hline & RMPV2 & 0.97 & & \\
\hline & RMPV3 & 0.96 & & \\
\hline \multirow{3}{*}{ RMSP } & RMSP1 & 0.88 & \multirow{3}{*}{0.79} & \multirow{3}{*}{0.92} \\
\hline & RMSP2 & 0.90 & & \\
\hline & RMSP3 & 0.90 & & \\
\hline \multirow{4}{*}{ SMT } & SMT1 & 0.88 & \multirow{4}{*}{0.79} & \multirow{4}{*}{0.94} \\
\hline & SMT2 & 0.87 & & \\
\hline & SMT3 & 0.93 & & \\
\hline & SMT4 & 0.89 & & \\
\hline \multirow{4}{*}{ TRUST } & $\mathrm{T} 1$ & 0.91 & \multirow{4}{*}{0.85} & \multirow{4}{*}{0.96} \\
\hline & $\mathrm{T} 2$ & 0.90 & & \\
\hline & T3 & 0.95 & & \\
\hline & T4 & 0.93 & & \\
\hline \multirow{2}{*}{ UA* } & UA2 & 0.83 & \multirow{2}{*}{0.68} & \multirow{2}{*}{0.81} \\
\hline & UA3 & 0.82 & & \\
\hline
\end{tabular}

*EMT1 and UA1 were dropped due to low loadings. 
TABLE 3: Discriminant Validity

\begin{tabular}{|c|r|r|r|r|r|r|r|r|r|}
\hline EMT & $\mathbf{0 . 8 5}$ & & & & & & & & \\
\hline INTENTION & -0.33 & $\mathbf{0 . 9 4}$ & & & & & & & \\
\hline OMSP & 0.29 & -0.01 & $\mathbf{0 . 8 4}$ & & & & & & \\
\hline OMPV & 0.36 & -0.20 & 0.57 & $\mathbf{0 . 8 9}$ & & & & & \\
\hline RMSP & -0.09 & 0.27 & -0.17 & -0.19 & $\mathbf{0 . 8 9}$ & & & & \\
\hline RMPV & -0.29 & 0.47 & -0.09 & -0.34 & 0.46 & $\mathbf{0 . 9 5}$ & & & \\
\hline SMT & -0.38 & 0.34 & -0.14 & -0.11 & 0.42 & 0.39 & $\mathbf{0 . 8 9}$ & & \\
\hline TRUST & -0.47 & 0.63 & -0.17 & -0.26 & 0.41 & 0.53 & 0.59 & $\mathbf{0 . 9 2}$ & \\
\hline \\
UA
\end{tabular}

We evaluate the validity and reliability of the formative construct (disposition to trust) by examining indicators' weights, loadings and their significance. The results are presented in Table 4. All indicator weights are highly significant $(p<0.001)$. Thus, all the indicators were kept.

TABLE 4: Formative Construct: Indicator Weights and Loadings

\begin{tabular}{|c|c|c|c|}
\hline Indicators & Weights & Loadings & T-statistics \\
\hline DT1 & 0.62 & 0.88 & $20.10 * * *$ \\
\hline DT2 & 0.54 & 0.84 & $20.68 * * *$ \\
\hline DT3 & 0.57 & 0.91 & $32.94^{* * *}$ \\
\hline DT4 & 0.53 & 0.90 & $44.83 * * *$ \\
\hline
\end{tabular}

Next, multicollinearity among indicators is tested by calculating the variance inflation factor (VIF). The acceptable value of VIF is 5 or lower [24].The values of VIF range from 1.10 to 1.83 (see Table 5), indicating that multicollinearity is not a problem with the formative construct.

TABLE 5: Formative Construct: Multicollinearity Results

\begin{tabular}{|c|c|c|c|c|}
\hline Dependent Variable & D1 & D2 & D3 & D4 \\
\hline D1 & & 1.104 & 1.761 & 1.692 \\
\hline D2 & 1.195 & & 1.832 & 1.694 \\
\hline D3 & 1.405 & 1.350 & & 1.111 \\
\hline D4 & 1.469 & 1.359 & 1.210 & \\
\hline
\end{tabular}

\section{Common Method Bias}

There is potential for common method bias for studies that use a self-reported survey [51]. To evaluate whether common method bias is an issue in this study, Harman's single factor test was conducted [50]. Common method bias exists if "a single factor emerges from unrotated factor solutions or a single factor explains the majority of the variance in the variables" [50: p. 536]. Factor analysis results suggest the presence of thirteen factors accounting for a total of $74.8 \%$ of the variance, of which the first factor accounts for $20.6 \%$ of the variance. Since a single factor does not account for the majority of variance in the variables, common method bias is not a concern in this study $[37,51]$. 


\section{Structural Model}

The primary evaluation criteria for the structural model are the $R^{2}$ measures and the values and significance of the path coefficients [23, 24]. Figure 2 and Table 6 present the structural model results. All hypotheses were supported by the data except two hypotheses ( $\mathrm{H} 2 \mathrm{~b}$ and $\mathrm{H} 3 \mathrm{~b})$.

Overall, the model explains $40 \%$ of the variance in the dependent variable, intention to adopt mobile payment (INTENTION) and $56 \%$ of the variance in consumer trust in mobile payment (TRUST). Trust has a statistically significant relationship with intention to adopt mobile payment (path $=0.63, t=16.40, p<0.001$ ). Therefore, trust appears to play an important role in consumer's intention to adopt mobile payment. Among all the trust antecedents, structural assurance (SMT), perceived environmental risk (EMT) and perceived reputation of mobile payment vendor (RMPV) exhibit strong relationships with consumer trust in mobile payment (TRUST) as predicted in the hypotheses $(p<0.001)$. The perceived reputation of the mobile service provider (RMSP), uncertainty avoidance (UA) and disposition to trust (DT) demonstrate a significant relationship with consumer trust in mobile payment (TRUST) $(p<0.05)$.

We also find support for $\mathrm{H} 2 \mathrm{c}$ : perceived reputation of mobile service provider (RMSP) and perceived opportunism of mobile service provider (OMSP) are negatively related (path $=-0.17$, $t=2.79, p<0.01)$. $\mathrm{H} 3 \mathrm{c}$ is also supported as perceived reputation of mobile payment vendor (RMPV) and perceived opportunism of mobile payment vendor (OMPV) are negatively related (path=-0.34, $t=6.04, p<0.001$ ). $\mathrm{H} 4 \mathrm{c}$ is supported as the relationship between perceived structural assurance (SMT) and perceived environmental risks (EMT) (path $=-0.38$, $t=7.90, p<0.001)$ are strongly significant.

We did not find support for $\mathrm{H} 2 \mathrm{~b}$ : the relationship between perceived opportunism of the mobile service provider (OMSP) and the level of consumer trust in mobile payment (TRUST) is not significant (path=0.04, $t=1.15$, ns). Similarly, we did not find support for H3b; the relationship between perceived opportunism of the mobile payment vendor (OMPV) and the level of consumer trust in mobile payment (TRUST) is not significant (path=-0.05, $t=1.19, \mathrm{~ns}$ ).

Among three control variables, we find two significant relationships: ethnicity and consumer trust in mobile payment (TRUST) (path $=-0.11, t=2.38, p<0.05$ ) and experience with mobile banking and consumer trust in mobile payment (TRUST) (path=0.13, $t=3.05, p<0.01$ ). The relationship between gender and consumer trust in mobile payment (TRUST) is insignificant (path=0.06, $t=1.63$, ns). From the analysis, the relationships between all the independent variables (e.g., RMSP, RMPV, EMT, SMT, DT, and UV) and dependent variable (e.g., TRUST) are found to be statistically significant despite the inclusion of the control variables (i.e., ethnicity, experience with mobile banking and gender). Thus, we conclude that the hypothesised relationships are still significant when the effects of ethnicity, gender and experience with mobile banking are controlled for. 


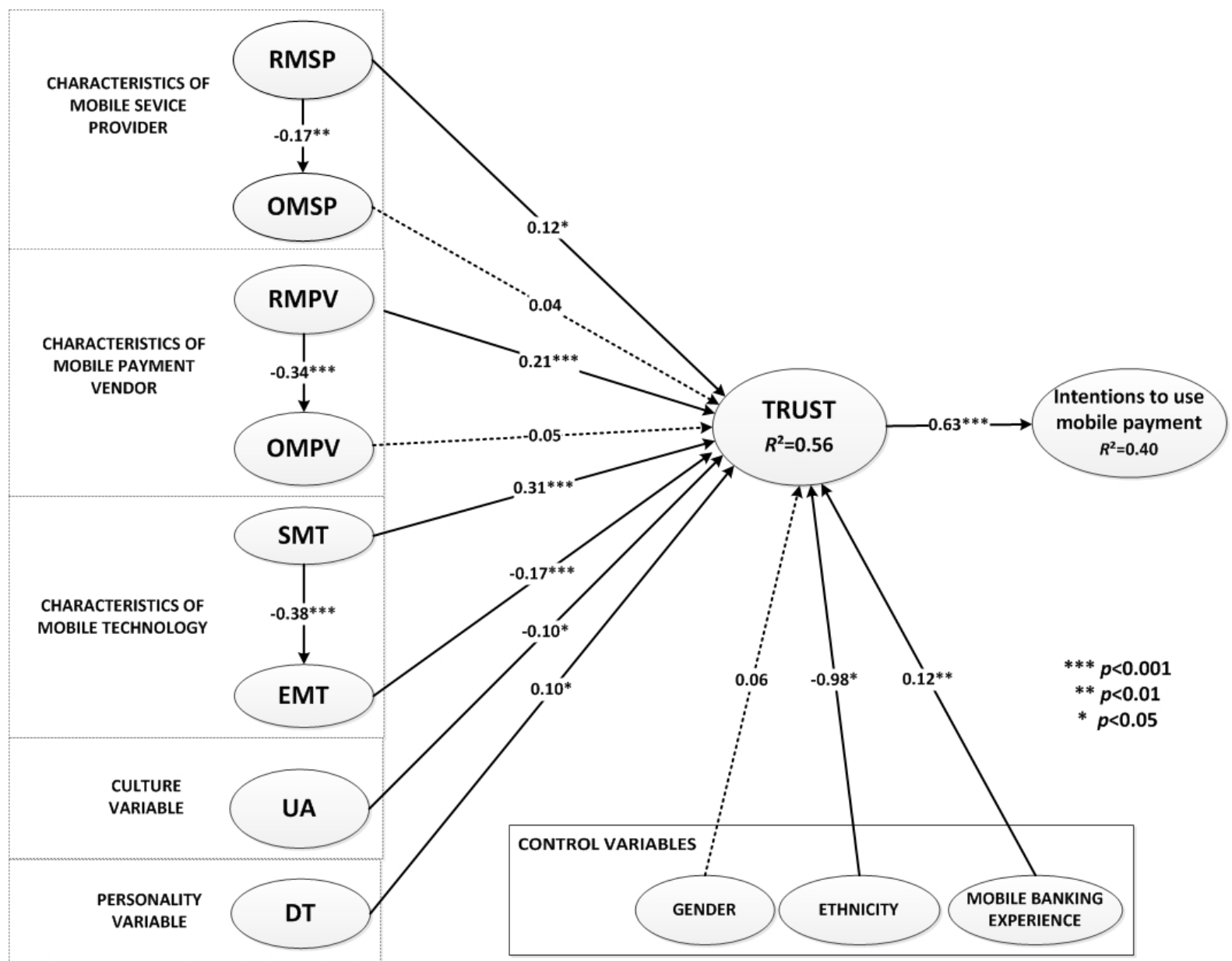

FIGURE 2: Results of Research Model

TABLE 6: Results of Hypotheses

\begin{tabular}{|c|c|c|c|c|}
\hline Paths & $\begin{array}{l}\text { Coefficient } \\
\text { (6) }\end{array}$ & $\begin{array}{c}\text { T-value } \\
(t)\end{array}$ & $R^{2}$ & Supported? \\
\hline H1: TRUST $\rightarrow$ INTENTION & $0.63^{* * *}$ & 16.39 & 0.40 & YES \\
\hline H2a: RMSP $\rightarrow$ TRUST & $0.12 *$ & 2.27 & 0.56 & YES \\
\hline $\mathrm{H} 2 \mathrm{~b}: \mathrm{OMSP} \rightarrow$ TRUST & 0.04 & 1.00 & & NO \\
\hline H2c: RMSP $\rightarrow$ OMSP & $-0.17 * *$ & 2.79 & & YES \\
\hline H3a: RMPV $\rightarrow$ TRUST & $0.21 * * *$ & 4.14 & & YES \\
\hline H3b: OMPV $\rightarrow$ TRUST & -0.05 & 1.19 & & NO \\
\hline H3c: RMPV $\rightarrow$ OMPV & $-0.34 * * *$ & 6.04 & & YES \\
\hline H4a: SMT $\rightarrow$ TRUST & $0.31^{* * *}$ & 5.21 & & YES \\
\hline H4b: EMT $\rightarrow$ TRUST & $-0.17 * * *$ & 3.67 & & YES \\
\hline H4c: SMT $\rightarrow$ EMT & $-0.38^{* * *}$ & 7.90 & & YES \\
\hline H5: UA $\rightarrow$ TRUST & $0.10^{*}$ & 2.03 & & YES \\
\hline H6: DT $\rightarrow$ TRUST & $-0.10 *$ & 2.05 & & YES \\
\hline
\end{tabular}

\section{DISSCUSSION AND CONCLUSION}

This research examined what constitute initial mobile payment trust and the influence of trust on the intention to adopt mobile payment. It followed McKnight et al.'s [44] trust typology and conceptualise initial mobile payment trust as trusting beliefs and trusting intentions. Three main entities that are objects of trust in mobile payment system are 
mobile service providers, mobile payment vendors and mobile technology. At an early stage of mobile payment adoption, consumers do not have previous interactions with these three parties. As a result, they may have uncertainties regarding mobile payment systems. These uncertainties include possible opportunistic behaviours conducted by mobile service providers and vendors, or the instable functioning of mobile technology. Therefore, trust serves to reduce the level of uncertainties or risks consumers may perceive which, in turn, leads consumers to have a higher propensity to adopt mobile payment. Our findings are in line with prior studies in Internet shopping and mobile banking [5, 7, 20, 27, 30, 34, 43]. We found that trust is an important predictor of intention to adopt mobile payment.

This study contributes to trust and IS adoption literatures by examining multidimensional trust antecedents in a mobile payment context. Despite previous research that examines trust in mobile payment, few studies explore antecedents of trust. In addition, Grabner-Kräuter and Kaluscha [21] suggest that future IS adoption studies should investigate the influence of culture on trust. In our study, we find a significant relationship between culture and trust, confirming that culture plays an important role in the formation of trust in new information systems.

Trust related characteristics of mobile service provider and mobile payment vendor including reputation and opportunism, may reduce the level of transaction specific uncertainties consumer may perceive towards a new technology. Consistent with findings in prior studies, our results show that the perceived reputation of mobile service provider and mobile payment vendor help consumers to mitigate the level of uncertainties and help them to establish trust. Although we did not find that perceived opportunism significantly influences the development of trust, our finding is similar to Chandra et al.'s [7] findings. A plausible reason might be that, according to a mobile payments readiness index report [39], New Zealand consumers have strong confidence in the legal system and its regulation of business. The law relating to information and technology communication is well developed and consumers believe that their financial assets and transactions are being well protected. As a result, consumers may believe that mobile service providers and vendors are less likely to violate the law by conducting opportunistic behaviours. Hence, the perceived opportunism of the mobile service provider and mobile payment vendor in New Zealand may not significantly influence mobile payment trust.

Another important entity in a mobile payment system is mobile technology. Our findings suggest that consumers consider the environment of mobile payment system risky to conduct transactions. However, consumers also believe that, having adequate structural assurance (e.g., third party guarantees) in place helps them to reduce the level of uncertainties, thus increasing their trust in the mobile payment system. These findings are in line with Chandra et al.'s [7] study.

Disposition to trust, which is a personality trait developed at one's early psychological development, affects one's initial trusting beliefs [43]. The result of our study shows that disposition to trust has a significant influence on mobile payment trust. This finding is in line with previous studies in other technologies $[16,19,32,61]$.

The finding of our study also highlights that uncertainty avoidance has a significant influence on the formation of mobile payment trust. Consumers with a higher level of uncertainty avoidance tend to avoid risks and consequently have a lower level of trust in mobile payment. In contrast, consumers with a lower level of uncertainty avoidance are 
likely to take risks, and place a higher level of trust in mobile payment. This finding is in line with previous studies $[9,30,60]$.

This study has several practical implications. Our findings offer a better understanding of the role of mobile service provider and mobile payment vendor in consumers' intention to adopt mobile payment. Consumers have uncertainties when they conduct transactions in a specific context and they evaluate their trust depending on the mobile service provider's and mobile payment vendor's reputation. Therefore, to reduce the level of uncertainty and engender consumer trust, it is crucial for mobile service providers and vendors to disclose relevant information to consumers. For example, mobile service providers may provide statements to consumers that their privacy is protected. Mobile payment vendors may provide receipts to consumers as a way to help consumers track their payment. Our results also point to the importance of mobile technology in consumers' intention to adopt mobile payment. To manage consumers' subjective risk perceptions of mobile technology, policymakers and service providers should develop adequate mobile technology-related regulations and safeguards. So, consumers believe that their financial transactions and personal data are being properly protected. These regulations and safeguards may include government regulations on ICT-related transactions, the enforcement of ICT-related laws, and an establishment of trusted institutions acting as guarantors.

To conclude, in the early stage of mobile payment adoption, it is crucial to provide information concerning the basic functioning and security of the mobile payment system to reduce consumers' uncertainty on mobile technology. In addition, information associated with characteristics of the mobile service provider and vendor and how they implement mobile technology should be disclosed to consumers to reduce their level of uncertainty and perceived risk.

\section{Limitations and Future Research}

The study is subject to a few limitations. First, this study targets potential consumers of mobile payment in Auckland, New Zealand. Therefore, readers should exercise caution to the generalisability of the results $[7,60]$. Secondly, at the time when we distributed surveys to participants, most of them have not had actual experience or know people who have experiences with mobile payment. This implies that our study focuses on the early stage of trust formation in mobile payment. Despite the lack of direct experience with mobile payment, we designed the survey instrument to ensure that respondents are aware of what a mobile payment transaction involves. In the survey instrument, we provide contextual details to explain various mobile payment parties along with examples. In addition, most informants (62.1\%) are already familiar with mobile banking. Therefore, we believe that their responses are reliable and valid.

Future studies may examine post adoption behaviours of mobile payment. Much research on trust in IS examines initial trust development. However, it is important to recognise that trust is a dynamic concept and consumers' trust is likely to change overtime. 


\section{REFERENCES}

[1] Andreev, P., Pliskin, N. and Rafaeli, S. "Drivers and inhibitors of mobile-payment adoption by smartphone users," International Journal of E-Business Research (IJEBR) 8, 3 (2012), 50-67.

[2] Awad, N. F. and Ragowsky, A. "Establishing trust in electronic commerce through online word of mouth: An examination across genders," Journal of Management Information Systems 24, 4 (2008), 101-121.

[3] Ba, S. "Establishing online trust through a community responsibility system," Decision Support System 31, 3 (2001), 323-336.

[4] Ba, S. and Pavlou, P. "Evidence of the effect of trust building technology in electronic markets: Price premiums and buyer behaviour," MIS Quarterly 26, 3 (2002), 243-268.

[5] Bhattacherjee, A. "Individual trust in online firms: Scale development and initial trust," Journal of Management Information Systems 19, 1 (2002), 213-243.

[6] Bhimani, A. "Securing the commercial Internet," Communications of the ACM 39, 6 (1996), 29-35.

[7] Chandra, S., Srivastava, S. C., and Theng, Y. L. "Evaluating the role of trust in consumer adoption of mobile payment systems: An empirical analysis," Communications of the Association for Information Systems 27, 1 (2010), 561-588.

[8] Cockburn, C. and Wilson, T.D. "Business use of the world wide web," International Journal of Information Management 16, 2 (1996), 83-102.

[9] Cyr, D. "Modelling web site design across cultures: Relationships to trust, satisfaction, and eloyalty," Journal of Management Information Systems 24, 4 (2008), 47-72.

[10]Dabholkar, P. A. "Consumer evaluations of new technology-based self-service options: An investigation of alternative models of service quality," International Journal of research in Marketing 13, 1 (1997), 29-51.

[11]Dahlberg, T., Mallat, N., and Öörni, A. "Trust enhanced technology acceptance modelconsumer acceptance of mobile payment solutions: Tentative evidence," Stockholm Mobility Roundtable (2003): 22-23.

[12]Dahlberg, T., Mallat, N., Ondrus, J., and Zmijewska, A. "Past, present and future of mobile payments research: A literature review," Electronic Commerce Research and Applications 7, 2 (2008), 165-181.

[13]De Ruyter, K., Wetzels, M., and Kleijnen, M. "Customer adoption of e-services: An experimental study," International Journal of Service Industry Management 12, 2 (2001), 184-207.

[14]Doney, P. M. and Cannon, J. P. "An examination of the nature of trust in buyer-seller relationships," Journal of Marketing 61, 2 (1997), 35-51.

[15]Doney, P. M., Cannon, J. P., and Mullen, M. R. "Understanding the influence of national culture on the development of trust," Academy of management review 23, 3 (1998), 601620.

[16]Gefen, D. "E-commerce: The role of familiarity and trust," Omega: The International Journal of Management Science 28, 6 (2000), 725-737.

[17]Gefen, D. "Reflections on the dimensions of trust and trustworthiness among online consumers," ACM SIGMIS Database 33, 3 (2002), 38-53.

[18]Gefen, D. and Straub, D.W. "Gender differences in perception and adoption of e-mail: An extension to the technology acceptance model," MIS Quarterly 21, 4 (1997), 389-400. 
[19]Gefen, D. and Straub, D.W. "Managing user trust in B2C eServices," E-service Journal 2, 2 (2003), 7-24.

[20]Gefen, D., Karahanna, E., and Straub, D. W. "Trust and TAM in online shopping: An integrated model," MIS quarterly 27, 1 (2003), 51-90.

[21]Grabner-Kräuter, S. and Kaluscha, E. A. "Empirical research in on-line trust: A review and critical assessment," International Journal of Human-Computer Studies 58, 6 (2003), 783812.

[22] Grazioli, S. and Jarvenpaa, S. L. "Perils of Internet fraud: An empirical investigation of deception and trust with experienced Internet consumers," IEEE Transactions on Systems, Man and Cybernetics-- Part A: Systems and Humans, 30, 4 (2000), 395-410.

[23]Hair, J. F., Hult, G. T. M., Ringle, C., and Sarstedt, M. A primer on partial least squares structural equation modeling (PLS-SEM). Sage Publications, 2013.

[24]Hair, J. F., Ringle, C. M., and Sarstedt, M. "PLS-SEM: Indeed a silver bullet," Journal of Marketing Theory and Practice 19, 2 (2011), 139-152.

[25]Henseler, J., Ringle, C. M., and Sinkovics, R. R. "The use of partial least squares path modeling in international marketing," Advances in International Marketing 20, 1 (2009), 277319.

[26] Hofstede, G. Culture's consequences: International differences in work-related values. Sage Publications, 1980.

[27]Jarvenpaa, S., Tractinsky, N., Saarinen, L. and Vitale, M. "Consumer trust in an Internet store: A cross cultural validation," Journal of Computer-Mediated Communication 5, 2 (1999). doi: 10.1111/j.1083-6101.1999.tb00337.x.

[28]John, G. "An empirical investigation of some antecedents of opportunism in a marketing channel," Journal of Marketing Research 21, 3 (1984), 278-289.

[29]Keramati, A., Taeb, R., Larijani, A. M. and Navid, M. "A combinative model of behavioral and technical factors affecting 'Mobile'-payment services adoption: An empirical study," Service Industries Journal 32, 9 (2012), 1489-1504.

[30]Kim, D. J. "Self-perception-based versus transference-based trust determinants in computermediated transactions: A cross-cultural comparison study," Journal of Management Information Systems 24, 4 (2008), 13-45.

[31]Kim, G., Shin, B., and Lee, H. G. "Understanding dynamics between initial trust and usage intentions of mobile banking," Information Systems Journal 19, 3 (2009), 283-311.

[32]Kim, K. K. and Prabhakar, B. "Initial trust and the adoption of B2C e-commerce: The case of Internet banking," ACM SIGMIS Database 35, 2 (2004), 50-64.

[33]Koufaris, M. and Hampton-Sosa, W. "The development of initial trust in an online company by new customers," Information and Management 41, 3 (2004), 377-397.

[34]Lee, M.K.O. and Turban, E. "A trust model for consumer Internet shopping," International Journal of Electronic Commerce 6, 1 (2001), 75-91.

[35]Liu, Z., Min, Q. and Ji, S. "An empirical study on mobile banking adoption: The role of trust," Second International Symposium on Electronic Commerce and Security, 2 (2009), 7-13. doi: 10.1109/ISECS.2009.150

[36]Luo, X., Li, H., Zhang, J., and Shim, J.P. "Examining multi-dimensional trust and multi-faced risk in initial acceptance of emerging technologies: An empirical study of mobile banking services," Decision Support Systems 49, 2 (2010), 222-234. 
[37]Malhotra, N. K., Kim, S. S. and Patil, A. "Common method variance in IS research: A comparison of alternative approaches and a reanalysis of past research," Management Science 52, 12 (2006), 1865-1883.

[38]Mallat, N. "Exploring consumer adoption of mobile payments - A qualitative study," Journal of Strategic Information Systems 16, 4 (2007), 413-432.

[39]MasterCard. "Mobile Payments Readiness Index: New Zealand," (2012). Retrieved from http://mobilereadiness.mastercard.com/reports/process.php?c\%5B\%5D=nz\&x=130\&y=22.

[40]McKnight, D. H. and Chervany, N. L. "What trust means in e-commerce customer relationships: An interdisciplinary conceptual typology," International Journal of Electronic Commerce 6, 2 (2002), 35-60.

[41]McKnight, D. H., Carter, M., Thatcher, J.B., and Clay P.F. "Trust in a specific technology: An investigation of its components and measures," ACM Transactions on Management Information Systems (TMIS) 2, 2 (2011), Article 12.

[42]McKnight, D. H., Choudhury, V., and Kacmar, C. "Developing and validating trust measures for e-commerce: An integrative typology," Information Systems Research 13, 3 (2002), 334359.

[43]McKnight, D. H., Cummings, L. L., and Chervany, N. L. "Initial trust formation in new organizational relationships," Academy of Management Review 23, 3 (1998), 473-490.

[44]Mercator Advisory Group. "Mobile payment 2013: Young adults and Minorities take the lead," (2013). Retrieve from http://www.mercatoradvisorygroup.com/Press Releases/Mobile Payments 2013 Young Adults and Minorities Take the Lead/

[45]Mukherjee, A. and Nath, P. "A model of trust in online relationship banking," International Journal of Bank Marketing 21, 1 (2003), 5-15.

[46]OECD. "Report on Consumer Protection in Online and Mobile Payments," OECD Digital Economy Papers, No. 204 (2012). OECD Publishing. Retrieved from http://dx.doi.org/10.1787/5k9490gwp7f3-en.

[47]Pavlou, P. A. "Consumer acceptance of electronic commerce: Integrating trust and risk with the technology acceptance model," International Journal of Electronic Commerce 7, 3 (2003), 101-134.

[48]Pavlou, P. A., Liang, H., and Xue, Y. "Understanding and mitigating uncertainty in online exchange relationships: A principal-agent perspective," MIS Quarterly 31, 1 (2007), 105-136.

[49]Pennington, R., Wilcox, H. D., and Grover, V. "The role of system trust in business-toconsumer transactions," Journal of Management Information Systems 20, 3 (2003), 197-226.

[50]Podsakoff, P. M. and Organ, D. W. "Self-reports in organizational research: Problems and prospects," Journal of Management 12, 4 (1986), 531-544.

[51]Podsakoff, P. M., MacKenzie, S. B., Lee, J. Y. and Podsakoff, N. P. "Common method biases in behavioral research: A critical review of the literature and recommended remedies," Journal of Applied Psychology 88, 5 (2003), 879-903.

[52]Ringle, C.M., Wende, S. and Will, S. SmartPLS 2.0 (M3) Beta. Hamburg. (2005). Http://www.smartpls.de.

[53]Rousseau, D. M., Sitkin, S. B., Burt, R. S., and Camerer, C. "Not so different after all: A crossdiscipline view of trust," Academy of Management Review 23, 3 (1998), 393-404.

[54]Salo, J. and Karjaluoto, H. "A conceptual model of trust in the online environment," Online Information Review 31, 5 (2007), 604-621. 
[55]Scevak, N. "Forrester Research mobile media and messaging forecast, 2010 to 2015 (Western Europe)," (2010). Retrieved from http://www.forrester.com/rb/Research/research mobile media and messaging forecast, 2010/q/id/57671/t/2.

[56]Shin, D. H. "Modeling the interaction of users and mobile payment system: Conceptual framework," International Journal of Human-Computer Interaction 26, 10 (2010), 917-940.

[57]Siau, K. and Shen, Z. "Building customer trust in mobile commerce," Communications of the ACM 46, 4 (2003), 91-94.

[58]Srite, M. and Karahanna, E. "The role of espoused national cultural values in technology acceptance," MIS Quarterly 30, 3 (2006), 679-704.

[59]Thair, A., Suhuai, L. and Peter, S. "Consumer acceptance of mobile payments: An empirical study," 4th International Conference on New Trends in Information Science and Service Science (NISS), 2010, 533-537.

[60]Vance, A., Elie-Dit-Cosaque, C., and Straub, D. W. "Examining trust in information technology artifacts: The effects of system quality and culture," Journal of Management Information Systems 24, 4 (2008), 73-100.

[61]Yang, G. and Mao, Y. "A research on the model of factors influencing consumer trust in mobile business," International Conference on E-Business and E-Government (ICEE), 2011, 15.

[62]Zhou, T. "The effect of initial trust on user adoption of mobile payment," Information Development 27, 4 (2011), 290-300. 